\title{
Calretinin expression in hippocampus of mouse offspring from dams treated with $\beta$-hydroxy- $\beta$-methylbutyrate
}

\author{
ALEKSANDRA KRAWCZYK, KAROL RYCERZ, JADWIGA JAWORSKA-ADAMU, \\ EWA TOMASZEWSKA*, PIOTR DOBROWOLSKI**
}

\author{
Department of Animal Anatomy and Histology, *Department of Animal Physiology, \\ University of Life Sciences in Lublin, Akademicka 12, 20-033 Lublin, Poland \\ **Department of Comparative Anatomy and Anthropology, Faculty of Biology and Biotechnology, \\ Maria Curie-Skłodowska University, ul. Akademicka 19, 20-033 Lublin, Poland
}

\section{Krawczyk A., Rycerz K., Jaworska-Adamu J., Tomaszewska E., Dobrowolski P. \\ Calretinin expression in hippocampus of mouse offspring from dams treated with $\beta$-hydroxy- $\beta$-methylbutyrate}

\section{Summary}

The aim of the study was the immunohistochemical evaluation of calretinin (CR) expression in the hippocampus of neonatal (P0) and 21-day-old (P21) male mice from dams that received $0.2 \mathrm{~g} / \mathrm{kg} \mathrm{b.w./day} \mathrm{of}$ $\beta$-hydroxy- $\beta$-methylbutyrate between the $26^{\text {th }}$ and $39^{\text {th }}$ day of pregnancy. The immunohistochemical peroxidaseantiperoxidase reaction was conducted on brain slices of offspring from control (C) and experimental (HMB) groups, using the specific antibody against CR. CR-immunopositive neurons of the hippocampal CA1 region and the dentate gyrus with the hilus were qualitatively and quantitatively assessed by means of an Olympus BX51 light microscope and the ImageJ 1.48v program. To demonstrate statistically significant differences, the Kruskal-Wallis test was used. The results of our studies revealed a decrease in CR expression intensity and the number of neurons only in the hilus of the dentate gyrus in both groups of mice (P0 and P21). The results indicate that HMB administration to pregnant dams may lead to damage or even loss of CR-immunopositive neurons in their offspring. This phenomenon may be related to calcium excess. Cells with CR expression inhibit the activity of other interneurons, causing a reverse of inhibition in principal neurons. The loss of cells with CR expression may interfere with the control and synchronisation of neuron excitability. In consequence, this may affect cognitive processes, memory and animal behaviour.

Keywords: calretinin, hippocampus, HMB, mouse

The structure and functions of the adult brain depend on many factors, including perinatal environmental conditions (14). It was demonstrated that the nutrition of pregnant rat dams influences the brain size, number of neurons, behaviour, learning and memory of their offspring (13).

Hippocampal regions (CA1-CA4) and the dentate gyrus with the hilus, which have a laminar structure, are responsible for memory processes (6). In rodents, this region is very sensitive to environmental factors, especially between the $18^{\text {th }}$ day of prenatal life and the $2^{\text {nd }}$ or $3^{\text {rd }}$ postnatal week (14). Proper hippocampus functioning depends, among others, on calcium ions, which in excess may lead to damage or even death of neurons. There are many systems which regulate intracellular $\mathrm{Ca}^{2+}$ concentration, including calcium binding proteins (CaBPs), e.g. calretinin (CR), which is a sen- sory protein, as well as a fast and slow calcium buffer (4). CR influences neuronal survival during calcium homeostasis disorders. Calcium ions in excess may lead to the activation of many enzymes (endonucleases, proteases, phospholipases) and to ultrastructure damages. Overexpression of this protein protects cells from a harmful increase in intracellular calcium ion concentration (5). However, the functions of this protein have not been fully explained $(2,17)$. In rodents, CR appears early in prenatal life and is determined in adult individuals approximately on the $21^{\text {st }}$ day of postnatal life (15). CR-immunopositive neurons were observed in all layers of hippocampal regions and the dentate gyrus, especially in its hilus (7).

In many experimental models of animal breeding, the positive effect of prenatal $\beta$-hydroxy- $\beta$-methylbutyrate (HMB) administration on skeleton and muscle devel- 
opment was demonstrated $(21,24)$. In vitro studies, on the other hand, suggest a neuroprotective effect of HMB via the activation of the mammalian target of the rypamycin (mTOR) trail and an increased expression of the myocyte enhancer factor-2 family (MEF2). These compounds play an important role in neuronal differentiation, survival and synaptic plasticity. Inhibition of their activity may be related to neuronal death and the development of neurodegenerative diseases (12). Until now, the prenatal effect of HMB on postnatal brain development and on the formation of neuronal nets in the hippocampus, which may influence learning, memory and cognitive processes, is not known. The aim of this study was to investigate the morphology and distribution of neurons with CR expression in the hippocampus of neonatal and 21-day-old male mice whose dams received $\mathrm{HMB}$ at a late stage of pregnancy.

\section{Material and methods}

Females of Cairo Spiny Mouse (Acomys cahirinus) (40-50 g b.w.) were divided into a control group $(\mathrm{n}=6)$ and an experimental group $(n=6)$, which received $\beta$-hydroxy- $\beta$ -methylbutyrate (HMB) (Sigma-Aldrich, St. Louis, Missouri, USA) at $0.2 \mathrm{~g} / \mathrm{kg}$ b.w./day between the $26^{\text {th }}$ and $39^{\text {th }}$ day of pregnancy. Pregnant dams were kept under constant conditions $\left(12 / 12 \mathrm{~h}\right.$ day/night) at $22^{\circ} \mathrm{C}$ and $55-60 \%$ air humidity. The animals were fed with standard fodder (LSM, Agropol S.J., Motycz, Poland) and had constant access to water. The study was approved by the First Local Ethical Committee in Lublin, Poland (8/2014).

The number of neonatal animals (P0) in a litter was 2-4 and did not differ between the two groups. Half of neonatal males from the control group $(\mathrm{C})(\mathrm{n}=6)$ and the experimental group (HMB) $(n=7)$ were euthanized by $\mathrm{CO}_{2}$ inhalation. The rest of control $(\mathrm{C})(\mathrm{n}=6)$ and experimental $(\mathrm{HMB})$ $(\mathrm{n}=7)$ males were grown till weaning and euthanized by $\mathrm{CO}_{2}$ inhalation on the $21^{\text {st }}$ day of life (P21).

Immediately after death, the brains were dissected, fixed in fresh and buffered $10 \%$ formalin (pH-7.0) for 12 hours at $4^{\circ} \mathrm{C}$ and embedded in paraffin blocks by a routine histological technique. The tissue blocks containing the hippocampus were cut into frontal $6 \mu \mathrm{m}$-thick slices.

Immunohistochemistry. To demonstrate calretinin (CR) immunoreactivity in neurons of the dorsal hippocampus (the $\mathrm{CA} 1$ region and the dentate gyrus with the hilus) in $\mathrm{P} 0$ and P21 male mice, the immunohistochemical peroxidase-antiperoxidase (PAP) reaction was carried out. The slices were treated with $0.4 \% \mathrm{H}_{2} \mathrm{O}_{2}$ for 30 minutes at room temperature to eliminate the activity of endogenous peroxidase. In order to remove background staining, the slices were incubated in normal goat serum (Sigma-Aldrich, St. Louis, Missouri, USA) for 20 minutes at room temperature. The antibodies and reagents (Sigma-Aldrich, St. Louis, Missouri, USA) were diluted in $0.5 \mathrm{M}$ TBS (Tris buffered saline, $\mathrm{pH}=7.6$ ) according to the producer's recommendations. The slices were incubated with the primary monoclonal rabbit anti$\mathrm{CR}$ antibody for $48 \mathrm{~h}$ at $4^{\circ} \mathrm{C}$. Subsequently, the secondary monoclonal goat anti-rabbit IgG and monoclonal peroxidase-antiperoxydase complex were used for 1 hour at room temperature each. The 3,3'diaminobenzidine tetrachloride (DAB) was used as a chromogen for 30 minutes at room temperature. The slices were rinsed in distilled $\mathrm{H}_{2} \mathrm{O}$, counterstained with Mayer's haematoxylin and mounted in DPX, respectively (Fluka, Buchs, Switzerland). The specificity control was conducted, omitting the primary antibody and replacing it with normal goat serum. CR-immunoreactive neurons from the hippocampal CA1 region and the dentate gyrus with the hilus were analysed and photographed under an Olympus BX51 light microscope (Olympus, Tokyo, Japan) with a digital camera (Olympus color view III). The reaction intensity of CR-positive neurons was specified as weak $(+)$, moderate $(++)$, intensive $(+++)$ and very intensive $(++++)$. Microphotographs were archived and analysed morphometrically.

Morphometric analysis. The average density of CR-positive cells in particular layers of the hippocampal CA1 region and the dentate gyrus with the hilus was evaluated in ImageJ $1.48 \mathrm{v}$ (National Institutes of Health, USA). The sections $(n=50)$ containing areas under study were selected randomly from each group of animals. For every section, 2 photos of the CA1 region and the dentate gyrus with the hilus were taken. A grid of squares of $2.5 \times 10^{-3} \mathrm{~mm}^{2}$ was imposed on randomly chosen microphotographs. The size of the squares was selected in such a way that the test area was the same for all layers studied in both age groups. To count the cells, squares which entirely covered a particular layer were chosen, but not more than 3 squares per photo in one layer. The CR-positive cells were counted until the results from 100 squares were obtained from every layer and every area of the brain investigated. In the two age groups (P0, P21), the average values of cell density were compared between the control and experimental animals.

Statistical analyses. Statistical analyses were performed by the R 3.0.2 program (Free Software Foundation's GNU General Public License, http://www.r-project.org/). To compare the results, a nonparametric Kruskal-Wallis test was used. The significance factor was set at 0.05 .

\section{Results and discussion}

The cells with CR expression were observed in neonatal male mice (P0) from the $\mathrm{C}$ group in all layers of the hippocampal CA1 region. In the SO, SP and SR, there were fusiform and oval neurons. Oval cells were present in the SLM (Fig. 1). In the dentate gyrus layers, the CR-immunoreactive cells were not observed. However, a neuropil of the SM inner part was stained as brown streak. In the hilus of the dentate gyrus, large and multiform neurons were located under the $\mathrm{SG}$ in a greater accumulation (Fig. 2). In the P0 males from the HMB group, CR-immunoreactive neurons were observed in the layers of the hippocampal CA1 region (Fig. 3). As in the control group, cells of the SM and SG layers of the dentate gyrus did not exhibit immunoreactivity for calretinin. Only the neuropil $(+)$ of the inner part of the SM was stained in the form of light-brown streak. Large and multiform neurons were present in the HMB group, compared with the control group (Fig. 4). 


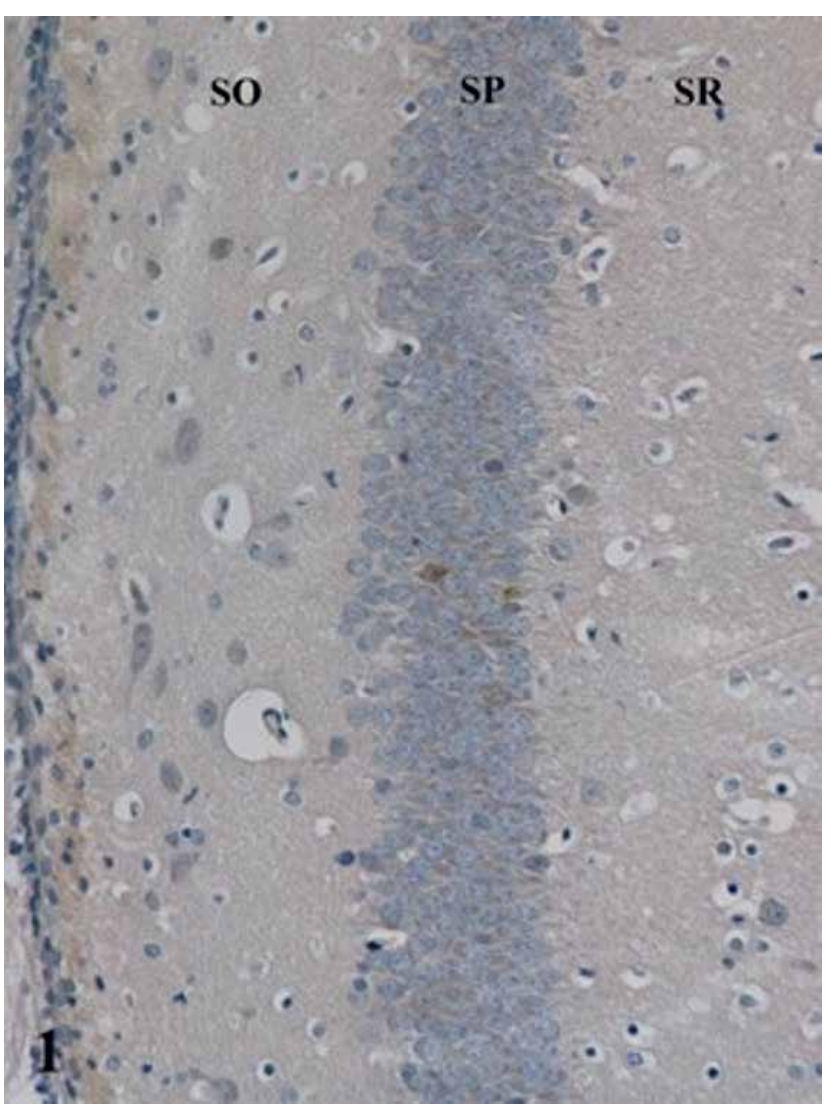

Fig. 1. CR-immunopositive neurons of hippocampal CA1 region of $\mathrm{P0}$ mice males from $\mathrm{C}$ group $(100 \times)$

Explanations: SO - stratum oriens; $\mathrm{SP}$ - stratum pyramidale; $\mathrm{SR}$ - stratum radiatum

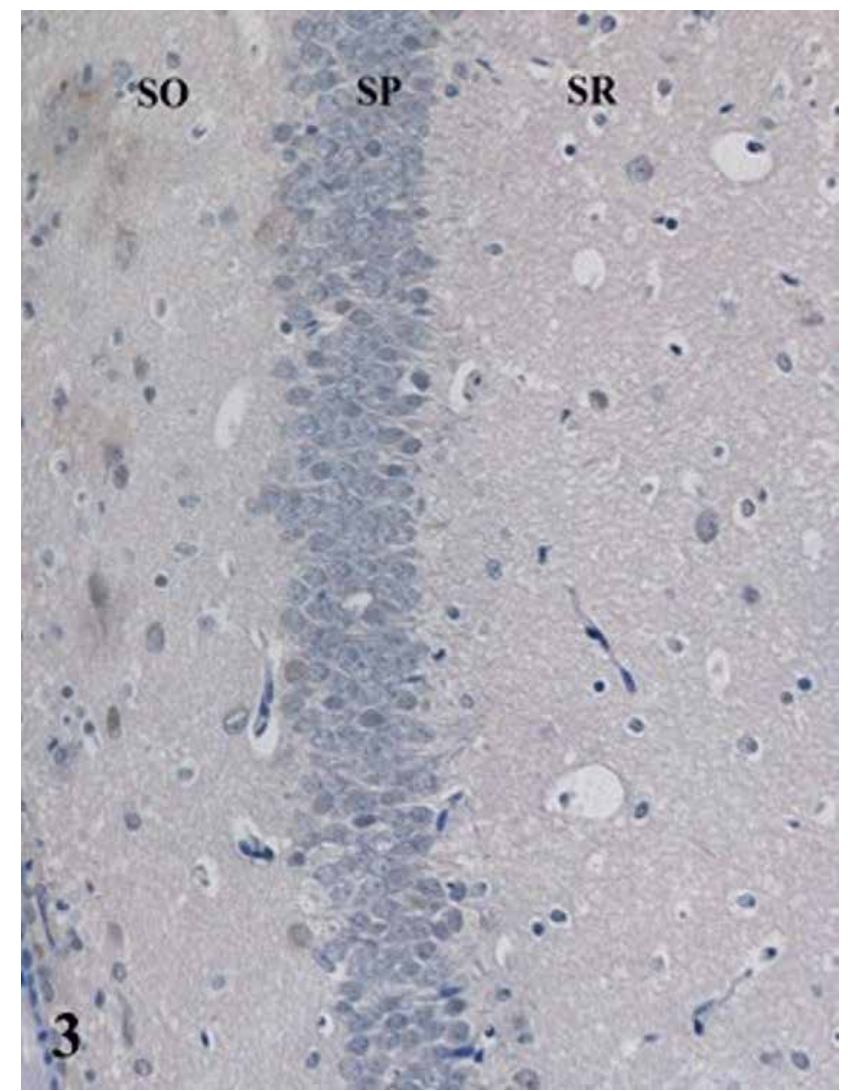

Fig. 3. CR-immunopositive neurons of hippocampal CA1 region of $\mathrm{PO}$ mice males from $\mathrm{HMB}$ group $(100 \times)$

Explanations: as in the legend of Fig. 1.

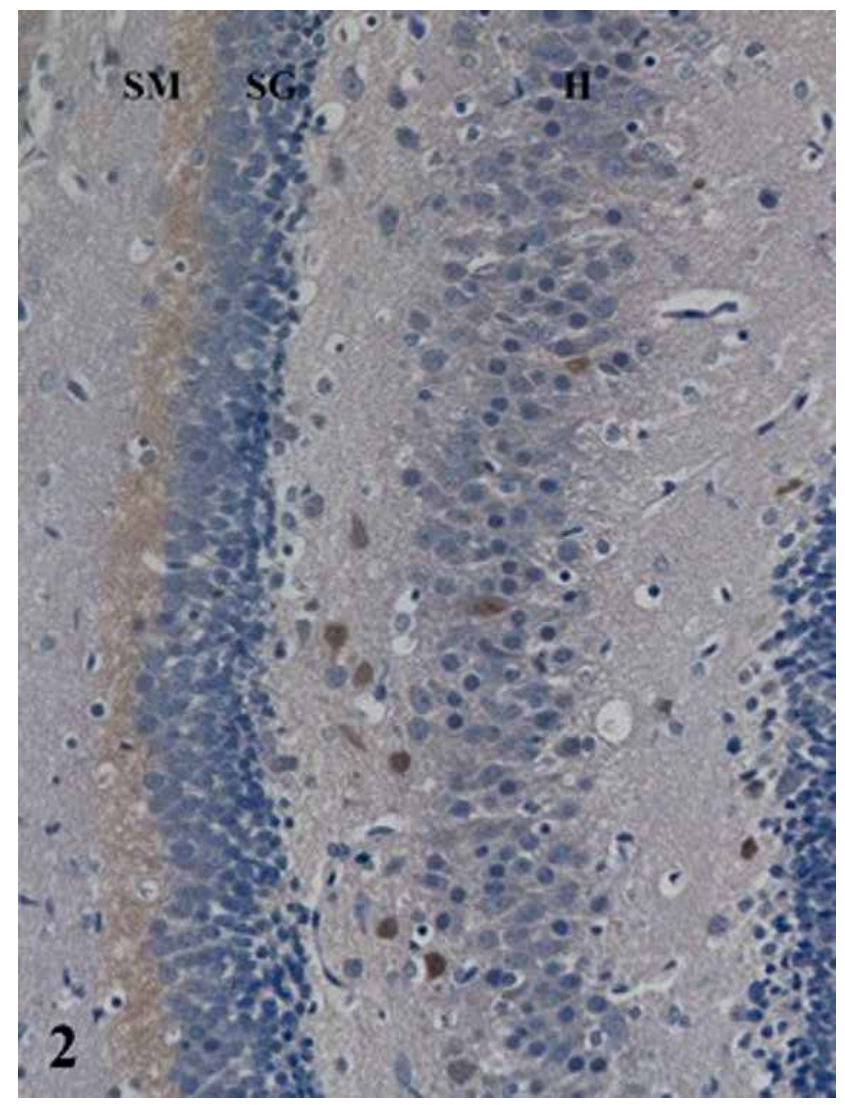

Fig. 2. CR-immunopositive neurons of dentate gyrus with hilus of P0 mice males from $C$ group $(100 \times)$

Explanations: SM - stratum moleculare; $\mathrm{SG}$ - stratum granulosum; $\mathrm{H}$ - hilus

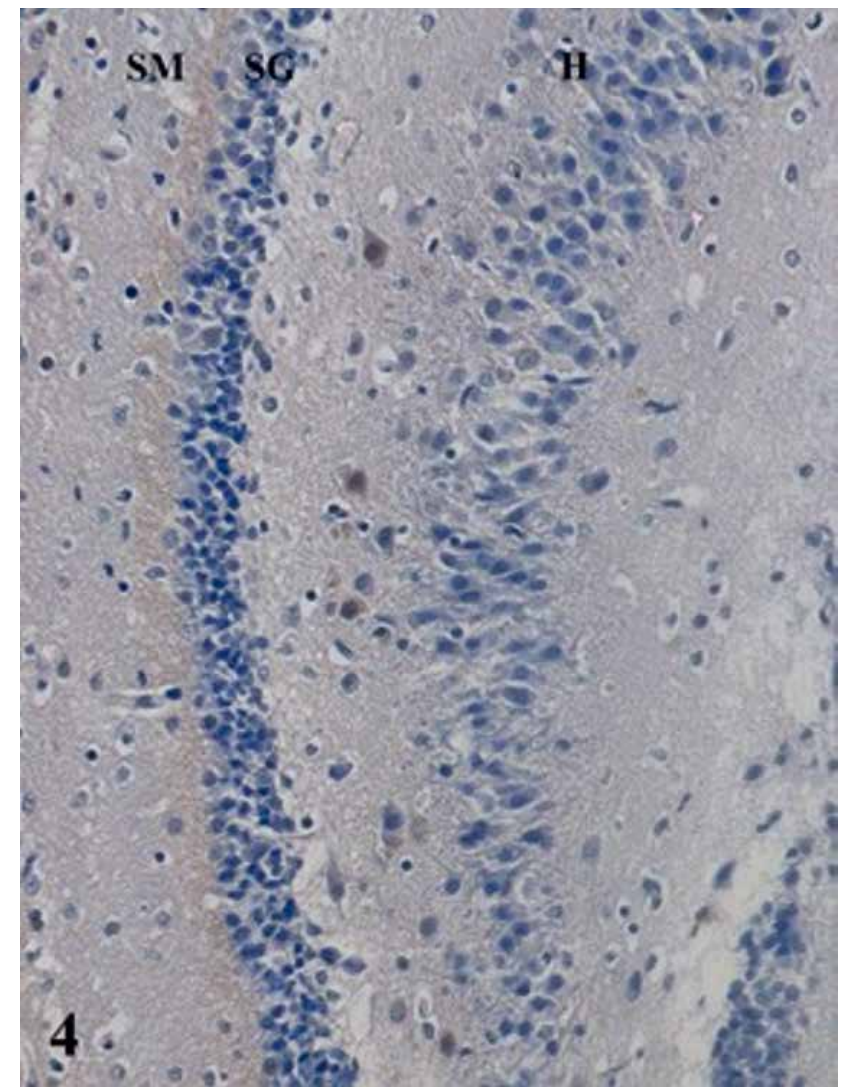

Fig. 4. CR-immunopositive neurons of dentate gyrus with hilus of P0 mice males from HMB group $(100 \times)$

Explanations: as in the legend of Fig. 2. 


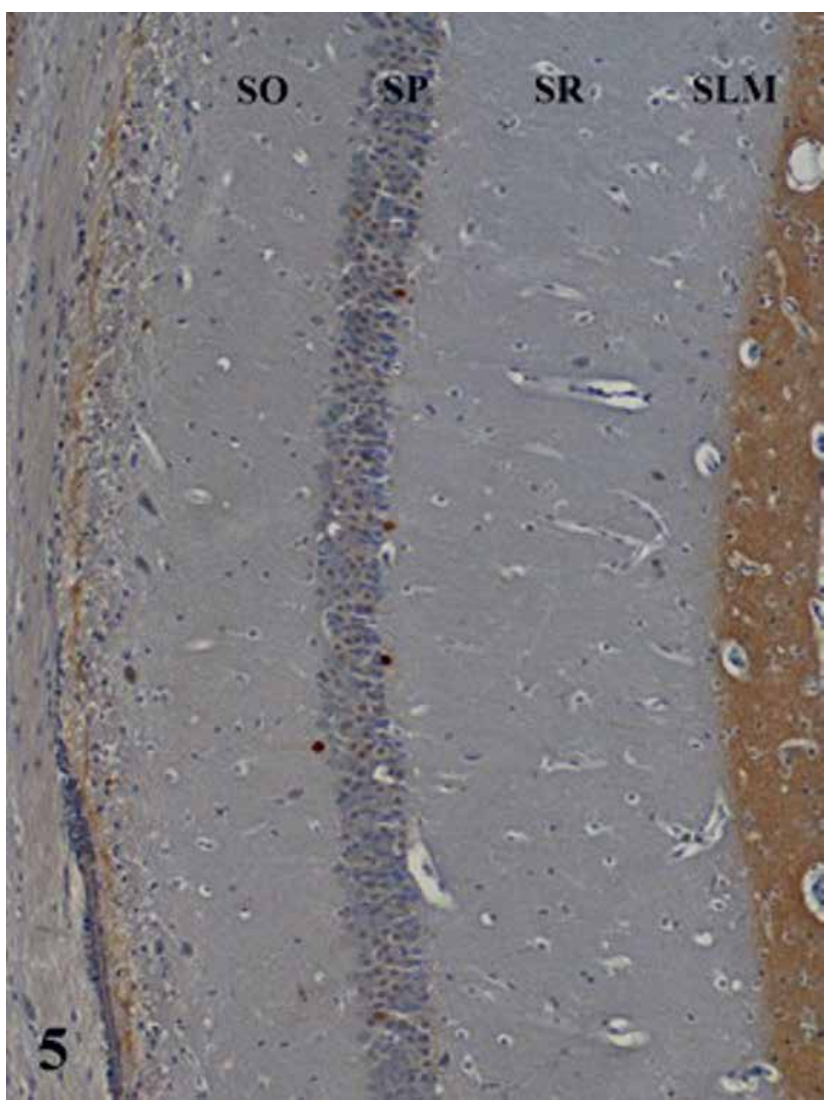

Fig. 5. CR-immunopositive neurons of hippocampal CA1 region of $P 21$ mice males from $C$ group $(400 \times)$

Explanations: SO - stratum oriens; SP - stratum pyramidale; SR - stratum radiatum; SLM - stratum lacunosum-moleculare

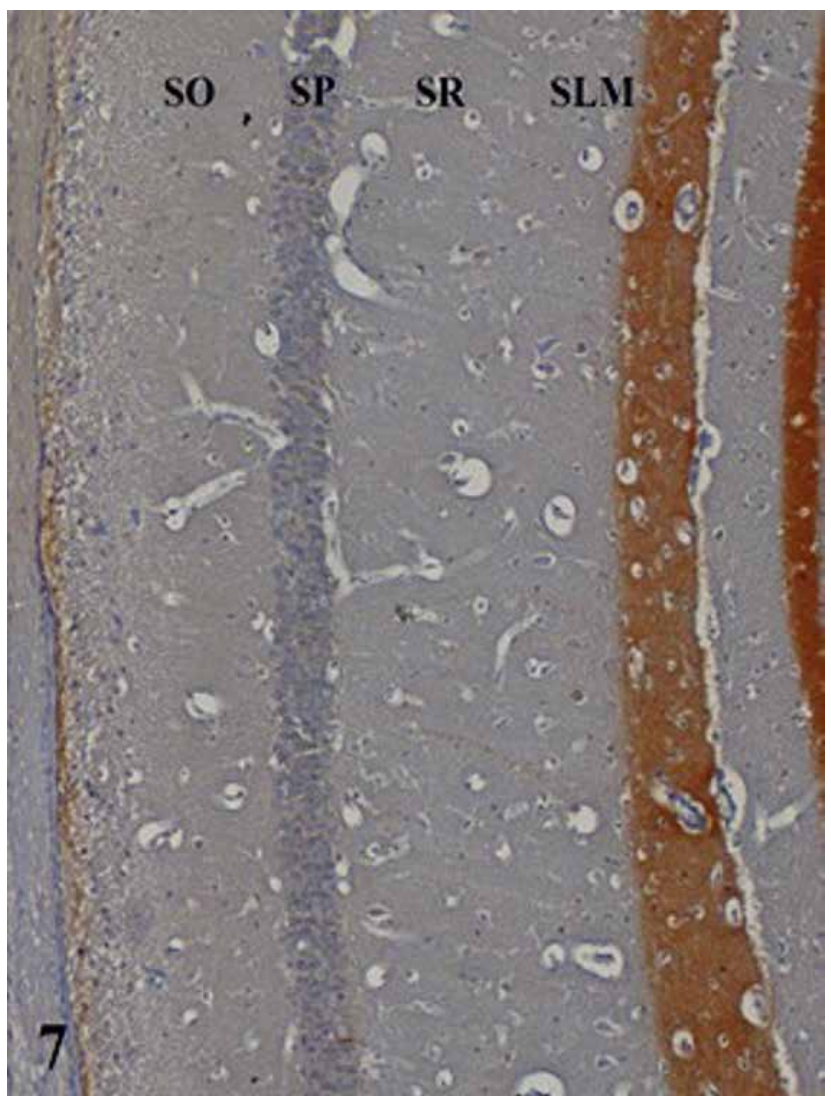

Fig. 7. CR-immunopositive neurons of hippocampal CA1 region of $P 21$ mice males from HMB group $(400 \times)$

Explanations: as in the legend of Fig. 5.

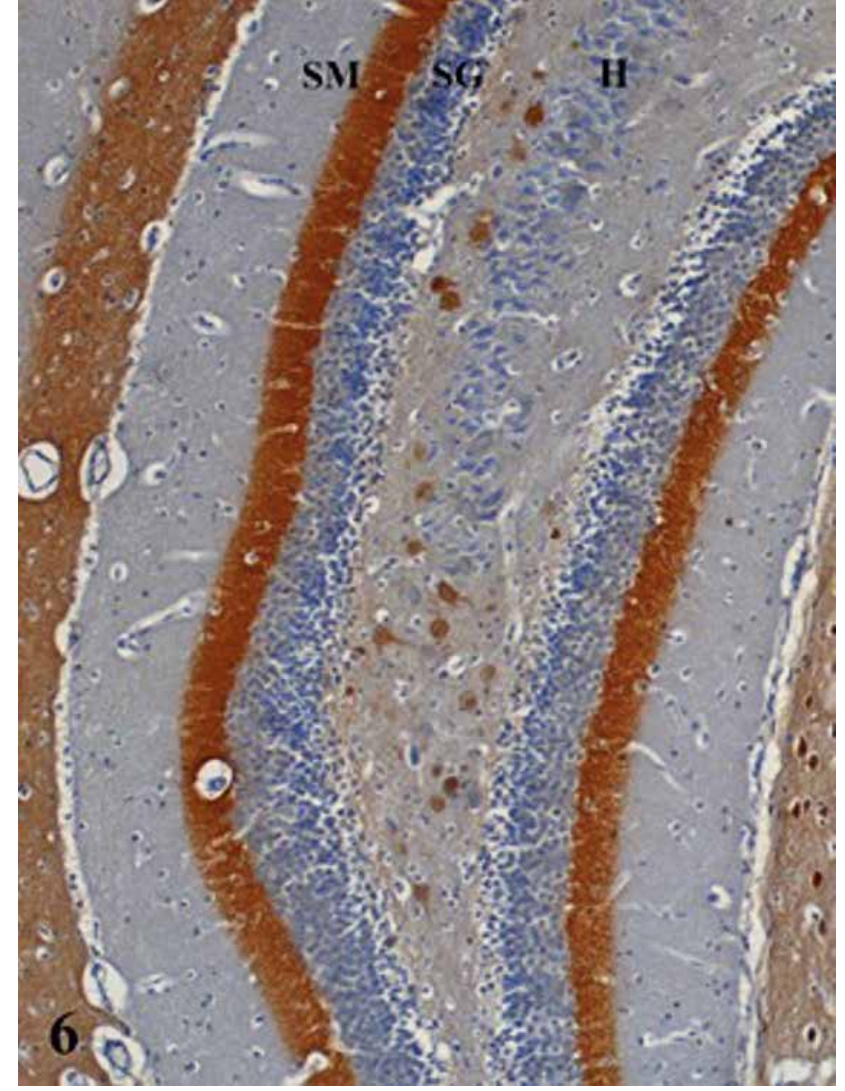

Fig. 6. CR-immunopositive neurons of dentate gyrus with hilus of P21 mice males from C group $(400 \times)$

Explanations: as in the legend of Fig. 2.

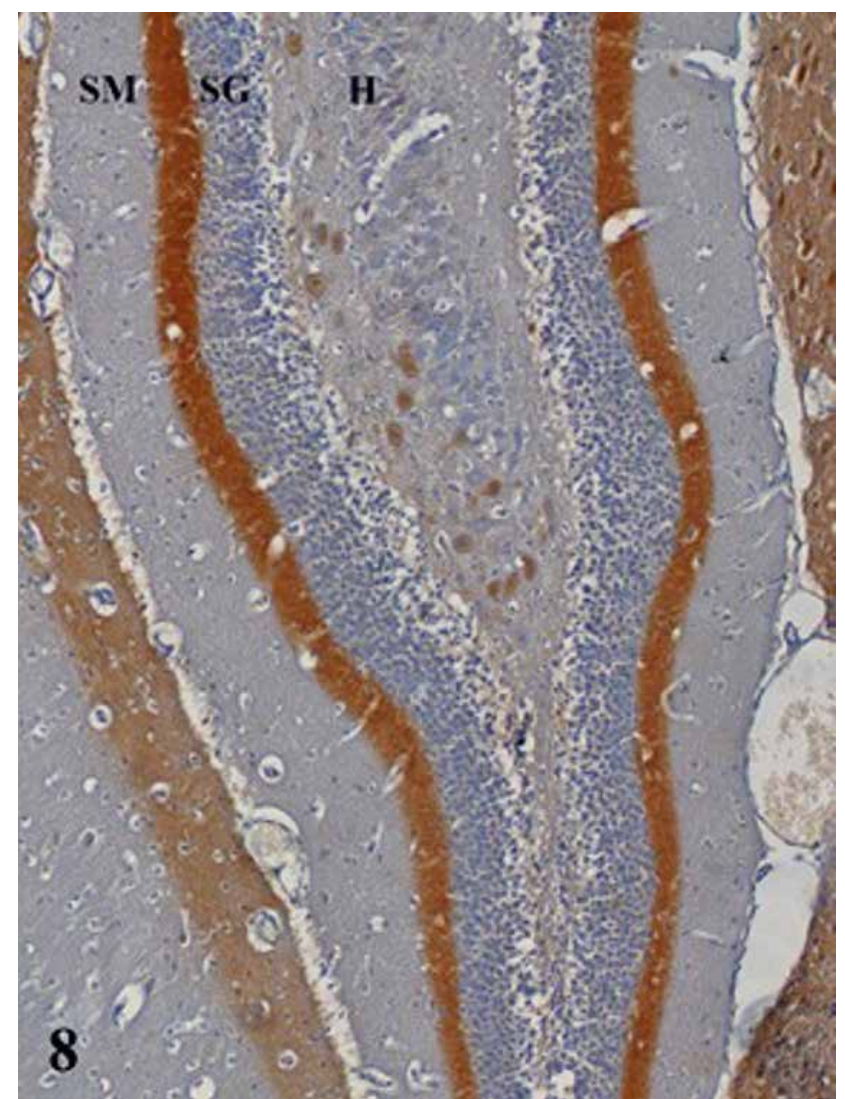

Fig. 8. CR-immunopositive neurons of dentate gyrus with hilus of P21 mice males from HMB group $(400 \times)$

Explanations: as in the legend of Fig. 2. 
In the hippocampal CA1 region of the 21-day-old animals (P21) from the $\mathrm{C}$ group, cells with $\mathrm{CR}$ expression were scattered in all layers examined. Fusiform and oval neurons were observed in the inner part of the SO layer. In the SP, round, fusiform and oval cells were located. Oval or fusiform neurons were also demonstrated in the SR and SLM (Fig. 5). Moreover, a streak of neuropil with an intensive $(+++)$ CR expression was located in the SLM part near the dentate gyrus. In the SM of the dentate gyrus, round cells were observed. Furthermore, a wide streak of neuropil located closer to the SG exhibited a very intensive $(++++)$ CR expression. Small and oval neurons were located in the SG near the hilus of the dentate gyrus. A significant accumulation of large and multiform cells with initial processes were found in the hilus (Fig. 6).

In males (P21) from the HMB group, fusiform and oval neurons were found in all layers of the hippocampal CA1 region. A layer of neuropil in the SLM near the dentate gyrus was characterised by an intensive CR expression (+++) (Fig. 7). Oval cells were observed in the SM layer of the dentate gyrus. A neuropil of the inner part of the SM was stained $(+++)$ in the form of brown streak. However, CR-immunoreactive cells were not found in the SG layer. In the hilus of the dentate gyrus, large neurons were present (Fig. 8).

The reaction intensity of CR-positive neurons in the hippocampus of $\mathrm{P} 0$ and $\mathrm{P} 21$ male mice are presented in Tab. 1.

The results of the morphometric analyses concerning the density of CR-immunoreactive neurons in the hippocampal CA1 region and the dentate gyrus with the hilus in P0 (Fig. 9) and P21 (Fig. 10) male mice confirmed the microscopic observations.

The results of our studies revealed that HMB administrated at $0.2 \mathrm{~g} / \mathrm{kg} \mathrm{b}$.w./day to pregnant mice $\left(26^{\text {th }}-39^{\text {th }}\right.$ day of pregnancy) caused a decrease in the density of neurons and the intensity of CR expression in the hilus of the dentate gyrus in males of both age groups ( $\mathrm{P} 0$ and P21). The decreased CR immunoreactivity and density of cells with CR expression demonstrated in this study may be related to changes in CR conformation, and therefore it is undetectable by immunohistochemical methods. Such a mechanism was proposed for studying the expression of parvalbumin, another calcium binding protein, in the rat's hippocampus after ischemia (10). However, the decrease in the density of cells with CR expression in the hilus of the dentate gyrus in neonates and 21-day-old males after HMB administration to their dams may suggest a damage or death of cells. It can be explained by a decrease in CR production, which in consequence increases intracellular calcium concentration, which may contribute to damage or even death of neurons. In the hilus of the dentate gyrus, most of CR-positive cells belong to inhibitory GABA-ergic interneurons $(3,11)$. Studies conducted on both humans and animals revealed that

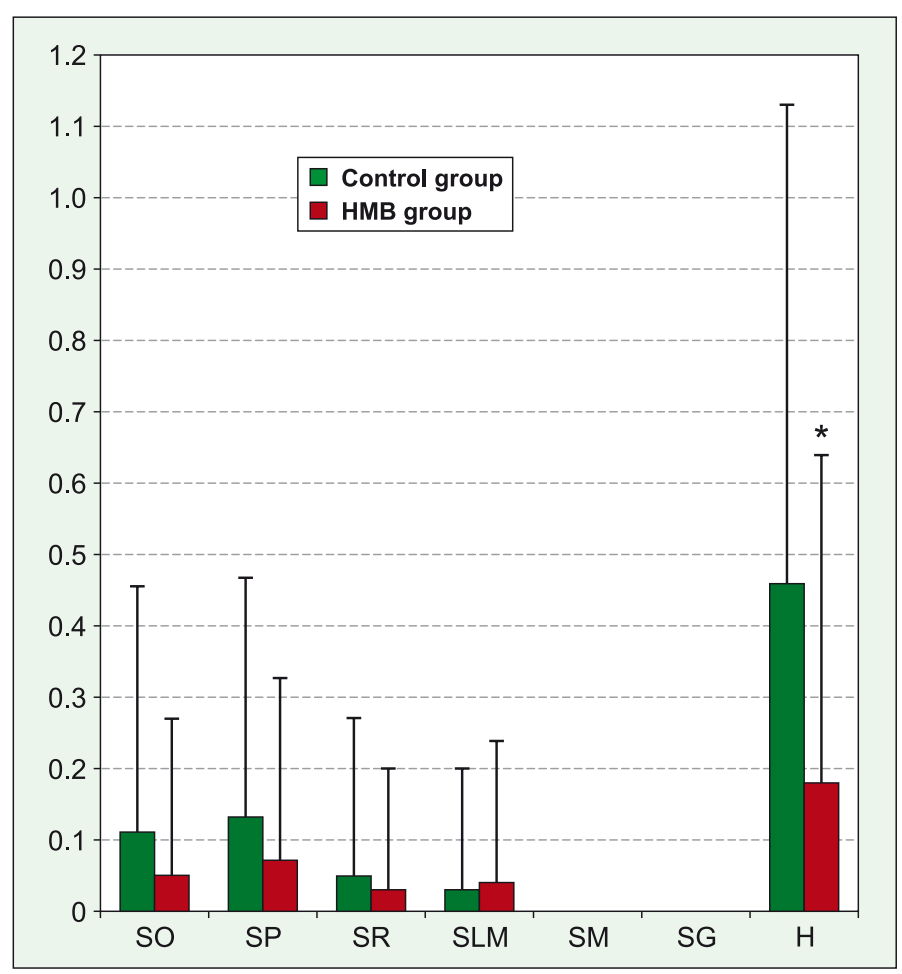

Fig. 9. The density of CR-immunopositive cells in layers of CA1 region of hippocampus and dentate gyrus with hilus in neonatal mice. Data shows mean density of CR-immunopositive cells in an area of $2.5 \times 10^{-3} \mathrm{~mm}^{2}$. Bars represent standard deviation

Explanations: * - statistically significant difference between control group and HMB group (Kruskal-Wallis, $\mathrm{p}<0.05$ ) related to the same layer; $\mathrm{SO}$ - stratum oriens; $\mathrm{SP}$ - stratum pyramidale; SR - stratum radiatum; SLM - stratum lacunosum-moleculare; $\mathrm{SM}$ - stratum moleculare; SG - stratum granulosum; $\mathrm{H}$ - hilus 


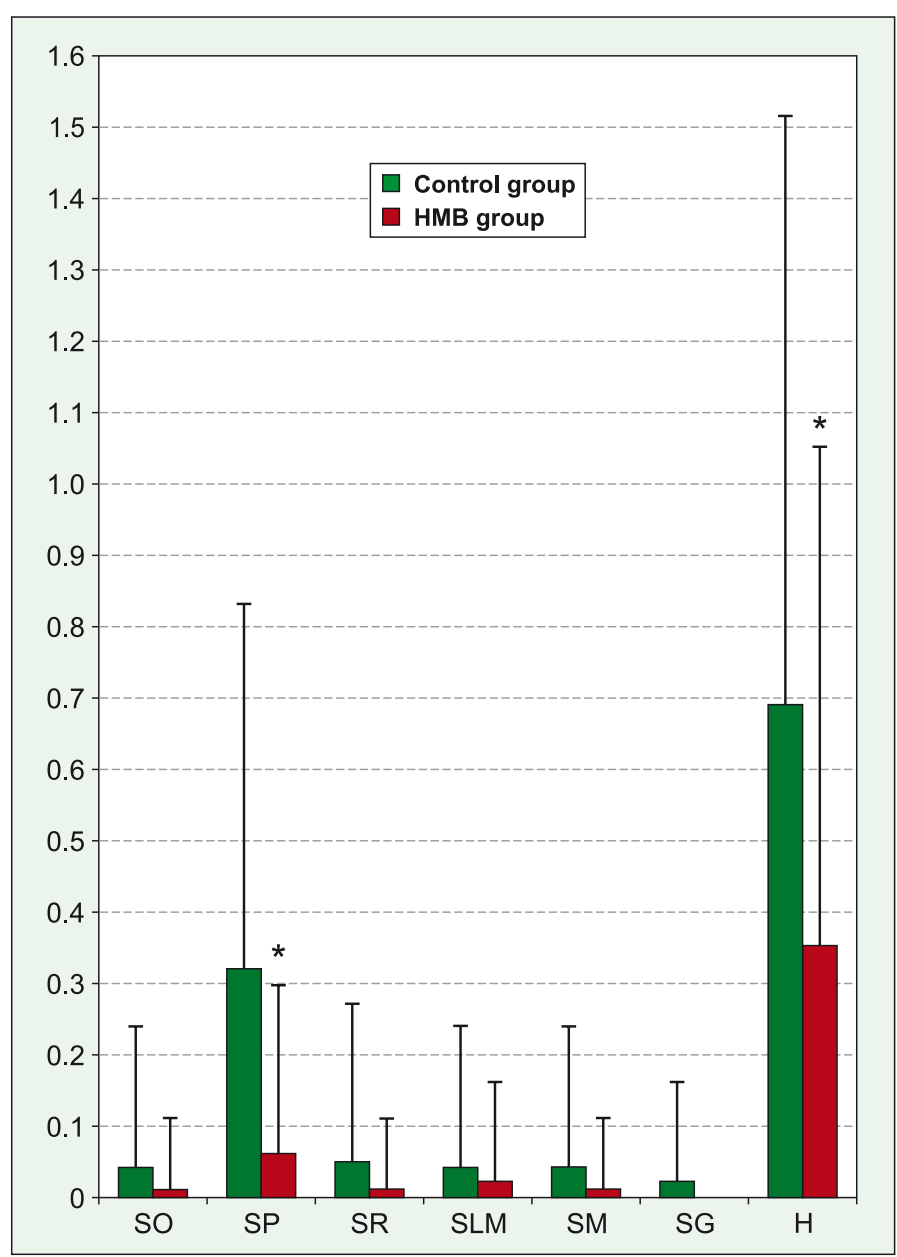

Fig. 10. The density of CR-immunopositive cells in layers of CA1 region of hippocampus and dentate gyrus with hilus in 21-day-old mice. Data shows mean density of CR-immunopositive cells in an area of $2.5 \times 10^{-3} \mathrm{~mm}^{2}$. Bars represent standard deviation

Explanations: as in the legend of Fig. 9.

GABA-ergic CR-positive neurons are sensitive to ischemia and epileptic alterations $(1,16,19,20,22,23)$. In animal epilepsy models, on the level of the light and electron microscope, a degeneration of hippocampal neurons with CR expression was observed. During these pathological stages, excitotoxic and calciumdependant damage or even death of neurons occurs (22). The GABA-ergic interneurons of the hilus form local connections between one another and synapses on dendrites solely in GABA-ergic interneurons with the expression of the vasoactive intestinal polypeptide, calbindin and somatostatin $(9,22)$.

Calretinin plays a crucial role in the stabilisation of neuronal nets and proper modulation of cell excitability. Neurons with CR expression inhibit the activity of other interneurons, causing a reverse of inhibition in the principal neurons. An attenuation of the ability to generate long-term potentiation (LTP) was demonstrated in mice incapable of CR synthesis, after tetanic stimulation of the hippocampus. Proper LTP induction was restored after the administration of GABA-A receptor antagonist (bicuculline). These results indicate that $\mathrm{CR}$ deficiency increases GABA release from cells connected to the principal neurons as a result of undue excitation of inhibitory interneurons (18).

However, numerous studies indicate that in the hilus of the dentate gyrus of adult mice, CR expression is found not only in GABA-ergic interneurons, but also in glutamatergic mossy cells, which was observed particularly in the ventral hippocampus. Mossy cell axons locate in the inner part of the SM of the dentate gyrus, where they innervate granular cells and interneurons $(3,8)$. This explains the presence of a CR-immunostained streak of neuropil in the SM layer next to the SG layer. In animals obtained from dams treated with $\mathrm{HMB}$, a weaker CR expression of the neuropil was demonstrated in comparison with control individuals. This phenomenon, together with a decrease in $\mathrm{CR}$ immunoreactivity observed in the hilus, may indicate a disrupted synthesis of CR in mossy cells.

The results of our studies demonstrate that HMB administrated to mice at a late stage of pregnancy disrupts the control and synchronisation of neuronal excitability via influence on neurons with CR expression in their offspring. The influence of the prenatal administration of HMB to dams on hippocampus activity requires further research.

\section{References}

1. Andre V., Marescaux C., Nehlig A., Fritschy J. M.: Alterations of hippocampal GABAergic system contribute to development of spontaneous recurrent seizures in the rat lithium-pilocarpine model of temporal lobe epilepsy. Hippocampus 2001, 11, 452-468.

2. Billing-Marczak K., Kuźnicki J. E.: Calretinin-sensor or buffer-function still unclear. Pol. J. Pharmacol. 1999, 51, 73-178.

3. Blasco-Ibanez J. M., Freund T. F.: Distribution, ultrastructure, and connectivity of calretinin-immunoreactive mossy cells of the mouse dentate gyrus. Hippocampus 1997, 7, 307-320.

4. Camp A. J., Wijesinghe R.: Calretinin: Modulator of neuronal excitability. Int. J. Biochem. Cell Biol. 2009, 41, 2118-2121.

5.Dong G., Gross K., Oiao F., Ferguson J., Callegari E. A., Rezvani K., Zhang D., Gloeckner C. J., Ueffing M., Wang H.: Calretinin interacts with huntingtin and reduces mutant huntingtin-caused cytotoxicity. J. Neurochem. 2012, 123, 437-446

6.El-Falougy H., Kubikova E., Benuska J.: The microscopical structure of the hippocampus in the rat. Brasil. Lek Listy 2008, 109, 106-110.

7.Freund T. F., Buzsáki G.: Interneurons of the hippocampus. Hippocampus 1996, 6, 347-470.

8. Fujise N., Liu Y., Hori N., Kosaka T.: Distribution of calretinin immunoreactivity in the mouse dentate gyrus: II. Mossy cells, with special reference to their dorsoventral difference in calretinin immunoreactivity. Neuroscience 1997, $82,181-200$

9. Gulyás A. I., Hájos N., Freund T. F.: Interneurons containing calretinin are specialized to control other interneurons in the rat hippocampus. J. Neurosci. 1996, 16, 3397-3411.

10.Johansen F. F., Tønder N., Zimmer J., Baimbridge K. G., Diemer N. H.: Short-term changes of parvalbumin and calbindin immunoreactivity in the rat hippocampus following cerebral ischemia. Neurosci. Lett. 1990, 120, 171-174.

11. Liu Y., Fujise N., Kosaka T.: Distribution of calretinin immunoreactivity in the mouse dentate gyrus. I. General description. Exp. Brain Res. 1996, 108, 389-403.

12. Lopez-Pedrosa J. M., Girôn M. D., Vilchez D., Manzano M., Rueda R., Salto R. OP054 Regulation of neuronal survival factors by $\beta$-hydroxy- $\beta$-methylbutyrate (HMB): future therapeutic implications. Clinical Nutrition Supplements 2011, 6,22 .

13. Lucas A.: Programming by early nutrition: an experimental approach. J. Nutr. 1998, 128, 401S-406S.

14. Lucassen P. J., Naninck E. F., van Goudoever J. B., Fitzsimons C., Joels M. Korosi A.: Perinatal programming of adult hippocampal structure and function; emerging roles of stress, nutrition and epigenetics. Trends Neurosci. 2013, 36, 621-631. 
15.Ludkiewicz B., Wójcik S., Spodnik E., Domaradzka-Pytel B., Moryś J.: Cholinergic innervation and calretinin-immunoreactive neurons in the hippocampus during postnatal development of the rat brain. Folia Morphol. 2002, 61, 7-14.

16. Magloczky Z., Freund T. F.: Impaired and repaired inhibitory circuits in the epileptic human hippocampus. Trends Neurosci. 2005, 28, 334-340.

17. Pochet R., Blachier F., Malaisse W., Parmentier M., Pasteelis B., Pohl V., Résibois A., Rogers J., Roman A.: Calbindin D28 in mammalian brain, retina, and endocrine pancreas: immunohistochemical comparison with calretinin. Adv. Exp. Med. Biol. 1989, 225, 435-443.

18. Schurmans S., Schiffmann S. N., Gurden H., Lemaire M., Lipp H. P., Schwam V., Pochet R., Imperato A., Böhme G. A., Parmentier M.: Impaired long-term potentiation induction in dentate gyrus of calretinin-deficient mice. Proc. Natl. Acad. Sci. USA 1997, 94, 10415-10420.

19. Suckling J., Roberts H., Walker M., Highley J. R., Fenwick P., Oxbury J., Esiri M. M.: Temporal lobe epilepsy with and without psychosis: exploration of hippocampal pathology including that in subpopulations of neurons defined by their content of immunoreactive calcium-binding proteins. Acta Neuropathol. 2000, 99, 547-554

20. Tang F. R., Chia S. C., Jiang F. L., Ma D. L., Chen P. M., Tang Y. C.: Calcium binding protein containing neurons in the gliotic mouse hippocampus with special reference to their afferents from the medial septum and the entorhinal cortex. Neuroscience 2006, 140, 1467-1479.

21. Tatara M. R., Krupski $W$.: Prenatal programming of skeletal development in the offspring: effects of maternal treatment with $\beta$-hydroxy- $\beta$-methylbutyrate (HBM) on femur properties in pigs at slaughter age. Bone 2007, 40, 1615-1622 .

22. Tóth K., Eross L., Vajda J., Halász P., Freund T. F., Maglóczky Z.: Loss and reorganization of calretinin-containing interneurons in the epileptic human hippocampus. Brain 2010, 133, 2763-2777.

23. Vliet E. A. van, Aronica E., Tolner E. A., Lopes da Silva F. H., Gorter J. A. Progression of temporal lobe epilepsy in the rat is associated with immunocytochemical changes in inhibitory interneurons in specific regions of the hippocampal formation. Exp. Neurol. 2004, 187, 367-379.

24. Wilkinson D. J., Hossain T., Hill D. S., Phillips B., Crossland H., Williams J., Loughna P., Churchward-Venne T. A., Breen L., Phillips S. M., Etheridge T., Rathmacher J. A., Smith K., Szewczyk N. J., Atherton P. J.: Effect of leucine and its metabolite $\beta$-hydroxy- $\beta$-methylbutyrate on human skeletal muscle protein metabolism. J. Physiol. 2013, 591, 2911-2923.

Corresponding author: dr Aleksandra Krawczyk, ul. Akademicka 12, 20-950 Lublin, Poland; e-mail: aleksandra.krawczyk@up.lublin.pl 